\title{
Articles
}

\section{Passive Integrated Transponder Tags: Review of Studies on Warmwater Fishes With Notes on Additional Species}

\author{
W. Chris Musselman, Thomas A. Worthington, Joshua Mouser, Desiree M. Williams, Shannon K. Brewer* \\ W.C. Musselman, T.A. Worthington, J. Mouser, D.M. Williams \\ Oklahoma Cooperative Fish and Wildlife Research Unit, 007 Agriculture Hall, Oklahoma State University, Stillwater, \\ Oklahoma 74078
}

\section{S.K. Brewer}

U.S. Geological Survey, Oklahoma Cooperative Fish and Wildlife Research Unit, 007 Agriculture Hall, Oklahoma State University, Stillwater, Oklahoma 74078-3051

\begin{abstract}
Although numerous studies have assessed retention and survival of passive integrated transponder (PIT) tags, data are scattered and information gaps remain for many diminutive fishes. Our study objectives were to 1) systematically review PIT tag studies and summarize retention, growth, and survival data for warmwater fishes; and 2) conduct a laboratory study to evaluate the retention, survival, and growth effects of intracoelomic-placed, half duplex PIT tags on six small-bodied species common to warmwater streams. Our systematic review suggested small sample sizes were common within PIT tag retention and survival studies (39\% with $n \leq 20)$ and that many experiments (15\%, 14 of 97) failed to use control fish as part of their evaluations. Studies focused primarily on short-term changes (15 d to $2 \mathrm{y}$ ) in tag retention and survival. Tag retention was equal to or greater than $90 \%$ in $85 \%$ of the experiments reviewed and median survival was $92 \%$. Growth was reported by fishes in the majority of reviewed studies. We found similar results after PIT tagging (peritoneum tagging using 12- or 23-mm half duplex tags) adult Cardinal Shiner Luxilus cardinalis, Central Stoneroller Campostoma annomalum, Greenside Darter Etheostoma blennioides, Orangethroat Darter Etheostoma spectabile, Slender Madtom Noturus exilis, and juvenile Smallmouth Bass Micropterus dolomieu. Tag retention for all species was high, with only one tag loss recorded after $60 \mathrm{~d}$. Survival was also high ( $\geq 88 \%)$ for all of our species with the exception of Orangethroat Darter (56\% survival). No significant difference in mean growth between treatment and control groups was found. Both our results and the findings of the literature review suggested generally high tag retention and low mortality in tagged fishes (across 31 species reviewed). However, within our study (e.g., Orangethroat Darter) and from the literature, examples of negative effects of PIT tagging on fishes were apparent, suggesting methodological testing is prudent before using PIT tags in field studies. We suggest future studies would benefit from addressing the behavioral implications that may be associated with tagging and examination of longer-term tag retention. Furthermore, standard reporting (i.e., sample sizes) in PIT tag studies would be beneficial, and use of control subjects or groups for statistical comparisons is needed.
\end{abstract}

Keywords: survival; tagging; retention

Received: December 6, 2016; Accepted: May 10, 2017; Published Online Early: June 2017; Published: December 2017 Citation: Musselman WC, Worthington TA, Mouser J, Williams DM, Brewer SK. 2017. Passive integrated transponder tags: Review of studies on warmwater fishes with notes on additional species. Journal of Fish and Wildlife Management 8(2):353-364; e1944-687X. doi:10.3996/122016-JFWM-091

Copyright: All material appearing in the Journal of Fish and Wildlife Management is in the public domain and may be reproduced or copied without permission unless specifically noted with the copyright symbol $\odot$. Citation of the source, as given above, is requested.

The findings and conclusions in this article are those of the author(s) and do not necessarily represent the views of the U.S. Fish and Wildlife Service.

* Corresponding author: shannon.brewer@okstate.edu 


\section{Introduction}

As smaller passive integrated transponder (PIT) tags have become available with technological advances, their use has increased in many studies in which individual identification is needed. Passive integrated transponder tags are glass-encapsulated microchips with unique identification, long operating time, and passive detection-characteristics that have increased the accuracy of mark-recapture estimates (Gibbons and Andrews 2004; Hewitt et al. 2010) and their application to an array of study objectives. Recaptures of PITtagged fishes have been used to estimate population size (Pine et al. 2003), growth (Walters et al. 2012), survival (Hewitt et al. 2010), movement (Skalski and Gilliam 2000), habitat use (Teixeira and Cortes 2007), predation (Ryan et al. 2003), behavior (McCormick and Smith 2004), and sampling efficiency (Price and Peterson 2010).

Small tags (9-12 mm) implanted into the body cavity (intracoelomic) have made PIT tags an effective option for studying small-bodied fishes (e.g., Dixon and Mesa 2011), but fish size remains a limiting factor (Prentice et al. 1990a; Lucas and Baras 2000; Skalski et al. 2009). Below a certain size, individuals may have slower growth and higher mortality after intracoelomic PIT tag injection (Prentice et al. 1990a). In addition, PIT tag retention is size dependent (Acolas et al. 2007), and the size threshold is associated with loss of fitness (i.e., reduced growth and survival), and unacceptable levels of tag retention are species specific (McCormick and Smith 2004; Jepsen et al. 2005). Although these relationships have been generally well established in the literature for salmonids (Skalski et al. 2009; Cooke et al. 2011), information is lacking for many warmwater fishes (Cooke et al. 2011).

Tag loss and tagging effects on growth and survival violate mark-recapture assumptions and bias parameter estimates that can handicap attempts to effectively manage populations (Burnham et al. 1987). Bolland et al. (2009) recommended retention and survival be evaluated for each species before field studies. This is especially important for juveniles and other small-bodied fishes where the risk of negative tag effects are increased (Prentice et al. 1990a). Although numerous studies have assessed PIT tag retention and survival, data are scattered and information gaps remain for fishes in certain ecosystems (e.g., warmwater streams; Cooke et al. 2011). Therefore, the study objectives were to 1) systematically review PIT tag studies and summarize retention and growth and survival data for nonsalmonid fishes; and 2) conduct a laboratory study to evaluate the retention, survival, and growth effects of intracoelomic PIT tags on six small-bodied species common to warmwater streams. Our laboratory study was conducted to ensure retention and survival were appropriate to follow up with a field-based study evaluating movement of select small-bodied fishes. Because our laboratory experiment was limited by sample size, we placed our experiments into context by comparing them with data from the literature to see whether the patterns observed in our study were consistent across other warmwater fishes. We also report patterns across studies to provide recommendations for future PIT tag studies.

\section{Methods}

\section{Literature review}

To provide an indication of the state of knowledge in relation to survival and retention of PIT tags in nonsalmonid fishes, we conducted a literature search by using ISI Web of Science in 2015. Four search strings were used, which were formed using the combinations of the following keywords: 'fish' AND 'passive-integrated-transponder' OR 'PIT Tag' AND 'retention' OR 'survival'. Within Web of Science, search results were screened based on the titles and abstracts and studies on salmonids, marine, and estuarine species and nonfish species (e.g., crayfish, salamanders) were omitted. The resulting literature was accessed and further filtered to remove studies that provided no information on survival or retention or were focused on anguilliform species.

Once the final set of literature was gathered, each paper was examined for general information: the year of publication, journal, taxonomic group studied, and objectives. For each paper, the number and identity of the species studied and the taxonomic family were recorded. The study objectives in relation to the use of PIT tags were categorized into seven groups, with studies sometimes belonging to multiple categories: 1 ) tag retention, 2) fish survival, 3) fish growth, 4) behavioral responses, 5) different PIT tagging methodologies, 6) different anatomical tagging locations, and 7) comparisons with other fish-marking procedures.

Within each individual study, more than one experiment was often identified, and was eventually used to summarize retention and survival for each species. For our analysis, we split studies into experiments if they used different species, different methodologies (e.g., tag size, tagging location, tagging method, PIT tags combined with other types of tags), different sizes of fish, different times, or different study locations (e.g., laboratory, fish pond, or field). If PIT tags were implanted in multiple locations on the same fish, each anatomical location was deemed an experiment. For each experiment, data were recorded on the study duration, location type, source of the fish (wild or hatchery), and sample size. The tag size (length and width), tagging method, and tagging location were also recorded. Where available, statistics on percentage of tag retention, fish survival and growth (positive or negative), and whether it was statistically different from a control group were collated. If a study had multiple experiments using a single species, we recorded these separately. If retention, survival, or growth statistics were reported at multiple time steps through an experiment, information from the last time step was used. 
Table 1. Characteristics of six warmwater fish species that were collected from Flint Creek, OK in 2012 to determine passive integrated transponder (PIT) tag retention in the laboratory. All fish were tagged in the peritoneum with 12- or 23-mm (tag size) half duplex PIT tags. The number of individuals $(N)$ varied by each species due to availability at sample locations. The mean initial total length (TL) and mean initial weight (WT) are provided for each study species. Variance was reported as SD.

\begin{tabular}{llcrrr}
\hline Common name & \multicolumn{1}{c}{ Scientific name } & N & TL \pm SD $(\mathbf{m m})$ & WT \pm SD $(\mathbf{g})$ & Tag size $(\mathbf{m m})$ \\
\hline Cardinal Shiner & Luxilus cardinalis & 24 & $91.1 \pm 9.6$ & $6.8 \pm 2.3$ & $12.0 \times 2.12$ \\
Central Stoneroller & Campostoma annomalum & 16 & $94.3 \pm 18.2$ & $7.3 \pm 4.5$ & $12.0 \times 2.12$ \\
Slender Madtom & Noturus exilis & 26 & $76.8 \pm 10.0$ & $3.4 \pm 1.4$ & $12.0 \times 2.12$ \\
Orangethroat Darter & Etheostoma spectabile & 18 & $60.2 \pm 5.7$ & $2.1 \pm 0.7$ & $12.0 \times 2.12$ \\
Greenside Darter & Etheostoma blennioides & 6 & $94.8 \pm 9.3$ & $6.5 \pm 1.7$ & $12.0 \times 2.12$ \\
Smallmouth Bass & Micropterus dolomieu & 50 & $148.0 \pm 10.8$ & $31.0 \pm 7.2$ & $23.0 \times 3.65$ \\
\hline
\end{tabular}

\section{Laboratory trials}

Laboratory experiments were conducted on six warmwater fishes in 2012 to assess tag retention and the effects on fish growth by intracoelomic PIT tagging. Wild fishes included in the laboratory study were Cardinal Shiner Luxilus cardinalis $(n=24)$, Central Stoneroller Campostoma annomalum ( $n=16)$, Greenside Darter Etheostoma blennioides ( $n=6)$, Orangethroat Darter Etheostoma spectabile ( $n=18$ ), and Slender Madtom Noturus exilis ( $n=26$; Table 1). Wild fishes were collected from Flint Creek, a third-order tributary of the Illinois River located in northeast Oklahoma by using standard seining methods (Bonar et al. 2009). Water temperatures at the time of fish collections ranged from 21 to $24^{\circ} \mathrm{C}$. Juvenile Smallmouth Bass Micropterus dolomieu $(n=50)$, acquired from the Kansas Department of Wildlife and Parks (Pratt Fish Hatchery, Pratt, KS), were also included in the study (Table 1). All fishes were acclimated to laboratory conditions for a minimum of $2 \mathrm{wk}$ and placed on a twice-daily feeding schedule with weekly water changes and daily water-quality monitoring (i.e., $\mathrm{pH}$, dissolved oxygen, ammonia, and temperature). Water temperatures in the laboratory were $23-25^{\circ} \mathrm{C}$ during the study. Dissolved oxygen and ammonia were maintained at acceptable levels and the $\mathrm{pH}$ was 6.8-8.2. All fishes were fed a dense-culture feed or freeze-dried krill (Aquatic Ecosystems, Apopka, FL).

Fish were haphazardly assigned to a treatment or control group. Before handling, all fish were anesthetized using tricaine methanesulfonate (MS-222; approximately $2.5 \mathrm{~mL} / \mathrm{L}$ stock solution of $20 \mathrm{~g}$ of MS-222 and $50 \mathrm{~g}$ of $\mathrm{NaHCO}_{3} / \mathrm{L}$, Hauer and Lamberti 2006). Upon loss of equilibrium, fish were measured to the nearest $1.0 \mathrm{~mm}$ (total length) and weighed to the nearest $0.1 \mathrm{~g}$. All treatment fishes, except Smallmouth Bass, were tagged with a 12-mm half duplex PIT tag (Oregon RFID, Portland, OR). Half duplex tags were chosen over full duplex tags because they are less susceptible to noise (i.e., interference), and $12 \mathrm{~mm}$ is the smallest tag size currently produced. Because of their larger size, Smallmouth Bass were tagged with a 23-mm half duplex PIT tag (Oregon RFID). Larger tag size is associated with greater read range and is advantageous in field studies (see description at https://www.oregonrfid.com/index.php?main_page= page\&id=31\&zenid=bk2kfb9p1c1 mev066aappu07h5).
Control fishes were subject to the same handling as treatment fishes (i.e., anesthetized, measured, weighed), but were not tagged. The same person (W.C.M.) conducted all tagging.

Tags were injected using a 12-gauge hypodermic needle (12-mm tag) or surgically implanted using a scalpel and manual insertion (23-mm tag) into the peritoneum from underneath the pectoral fin following methods of Prentice et al. (1990b). Smaller species (e.g., minnows, darters, and madtoms) were placed in an individual 38-L aquarium with a control fish of the same species. Smallmouth Bass were placed into three replicate 2,400-L tanks in groups of ten (control $n=5$, treatment $n=5$ ). These holding densities were within the range found under field conditions (S.K. Brewer, unpublished data).

Experiments lasted a minimum of $30 \mathrm{~d}$. Fish were then removed from the tanks, anesthetized, measured (total length), weighed, and scanned with a hand-held PIT tag reader (DataTracer, Oregon RFID) for the presence of the tag. Treatment fishes that retained tags after $30 \mathrm{~d}$ were held for an additional $30 \mathrm{~d}$, but they were placed in larger 2,400-L tanks. Treatment Smallmouth Bass were still kept in separate 2,400-L tanks to avoid predation on smaller study species. At the end of the experiments, fish were euthanized using a lethal dose of MS-222, measured, weighed, and then preserved in $10 \%$ formalin.

Growth rates (final weight - initial weight), survival (percentage alive after the trial), and tag retention (percentage retaining tags after the trial) were calculated at the conclusion of the experiment. Significant differences $(\alpha=0.05)$ in mean growth for treatment vs. control fish by species were assessed using a Welch's $t$-test in R (R Core Team 2012). Welch's t-test does not make the assumption of homogeneity of variance and uses a correction to adjust degrees of freedom (Field et al. 2012). Normality of growth data by species and treatment were evaluated using a Shapiro-Wilk test.

\section{Results}

\section{Literature review}

The literature search returned 167 individual articles of which 29 met the review criteria (e.g., retention and survival) of PIT tag studies on non-salmonid fishes. Publication dates ranged from 1989 to 2015, with a 
general increase in publications since 2009. There was a clear bias in the journals where studies were published, with only nine outlets represented. More than half (15 of 29) of the studies were published in the North American Journal of Fisheries Management. Additional journals represented were the Journal of Applied Ichthyology ( $n$ $=3)$, Ecology of Freshwater Fish $(n=2)$, Transactions of the American Fisheries Society $(n=2)$, North American Journal of Aquaculture $(n=2)$, Progressive Fish-Culturist $(n=2)$, and three other journals with one publication each.

Studies were biased toward those carried out in the United States (72\%; including one field study in Lake Erie, United States and Canada). Three studies were conducted in the UK; two in Belgium; and one each in Canada, Germany, and Japan. The majority of studies focused on a single species $(n=25)$, with one study containing information on two species and three studies comparing three species. Information was reviewed on 31 species with Muskellunge Esox masquinongy $(n=4)$, Largemouth Bass Micropterus salmoides $(n=2)$, and Burbot Lota lota $(n=2)$ represented in multiple studies. The 31 species represented 15 families, with most species belonging to five families: Cyprindae (26\%), Cottidae (10\%), Ictaluridae (10\%), and Lepisosteidae (10\%).

The papers covered multiple objectives, but those objectives were not equally represented. As expected given the search terms, after tag retention, fish survival was the most common study area ( $83 \%$ of studies; Table 2). Information on fish growth in relation to tagging was reported in almost half the studies $(n=12)$, whereas studies comparing PIT tags to other tagging methods were also well represented ( $41 \%$ of studies). Nine studies compared different anatomical tagging locations, whereas different insertion methods (e.g., injecting vs. incisions) were the subject of four papers. Studies reporting information on fish behavior focused on swimming performance $(n=2)$, feeding $(n=2)$, and net avoidance $(n=1)$.

Studies also varied in the location where they were conducted, the study duration, and the sample size. A majority of the 29 studies was conducted in the laboratory ( $n=15)$, but field $(n=4)$ and aquaculture pond $(n=9)$ setups were also used. There was also one paper that included both lab and pond setups. Study duration was highly variable, ranging from $15 \mathrm{~d}$ to more than $2 \mathrm{y}$. Wild fish $(n=16)$ were more commonly used in studies compared to hatchery-raised fish $(n=13)$. The number of fish tagged per experiment ranged from 4 to 930 individuals (median $=32$ ).

Tagging methodology was mainly split between tags implanted into the peritoneal or dorsal musculature by using injection, or into the peritoneal by incision. The most common methods and locations reported were PIT tags inserted via incision into the peritoneal cavity and injected into the dorsal musculature $(41 \%$ of studies each). Other well-represented methods were injection into the peritoneal cavity $(n=11)$. Injection into the cheek musculature and operculum were reported in two papers each. The least common methods reported were injection into the isthmus and esophageal implants, with one paper each.

We identified several experiments, which were used to summarize tag retention and fish survival by species. Statistics on tag retention and fish survival were available from the majority of the experiments (Table 2). Across all experiments, retention ranged from 13 to $100 \%$. Tag retention was equal to or greater than $90 \%$ in $85 \%$ of experiments. Fish survival was more variable, although survival was equal to or greater than $90 \%$ in $57 \%$ of experiments, ranging between 0 and 100\% (median = $92 \%$ ). Control groups were used in 83 of 97 experiments, allowing significant differences in survival to be calculated for some studies (Table 2). Twenty-six of the control-paired experiments did not report statistics relating survival between treatment groups. For the remaining experiments, there was no difference in survival for the majority ( $n=41$ ); however, significantly lower survival was reported for the treatment group on sixteen occasions. Of the 47 experiments where growth data were available, growth was reported in all but one instance. Lastly, sample sizes varied greatly across experiments with 39\% (38 of 97) of studies using 20 or fewer individuals.

\section{Laboratory trials}

The mean total length of the experimental fishes (Table 3; Tables S1 and S2, Supplemental Material) ranged from $60 \mathrm{~mm}$ for Orangethroat Darter to $148 \mathrm{~mm}$ for juvenile Smallmouth Bass. All species growth data fit the assumption of normality. Survival $24 \mathrm{~h}$ post tagging was $100 \%$ for all species and remained high for the study duration (Table S3, Supplemental Material). After 30 days, treatment survival was $100 \%$ for Cardinal Shiner, Central Stoneroller, Greenside Darter, and Slender Madtom, with a single mortality for each of Smallmouth Bass and Orangethroat Darter (Table 3). After $60 \mathrm{~d}$, there was a single Central Stoneroller mortality and three additional Orangethroat Darter mortalities. Survival remained constant for all other species (Table 3). Tag retention after 60 d was $100 \%$ for all species except Orangethroat Darter. Orangethroat Darter lost a single tag in the first $30 \mathrm{~d}$, reducing retention to $88 \%$, but the overall retention percentage dropped further at $60 \mathrm{~d}$ due to mortalities (e.g., four of five fish retained tags; Table 3). There were no significant differences in mean growth between treatment and control groups for all species (Figure 1).

\section{Discussion}

The use of PIT tags in the conservation and management of fish species is a valuable tool; however, understanding tagging limitations (i.e., changes to fish fitness and the likelihood of tag retention) is critical. For all our study species, we observed high PIT tag retention, with only a single Orangethroat Darter losing a tag. This is consistent with the findings of the review in which reported retention across the experiments was high. Our 


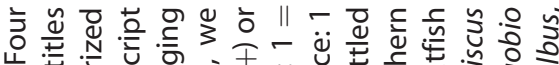

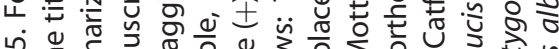

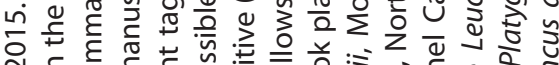

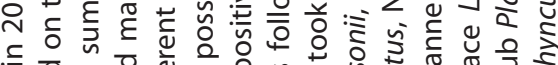

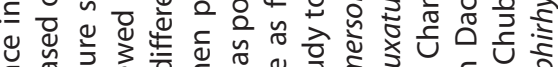

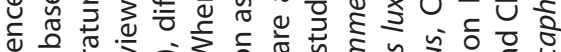

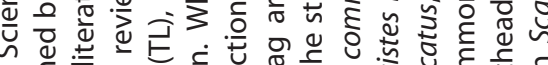
to

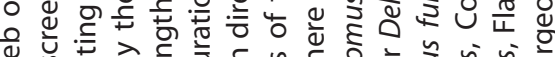

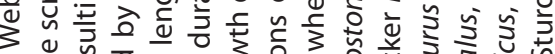

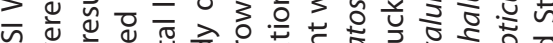

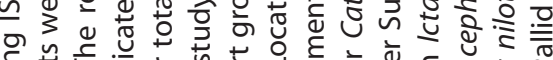

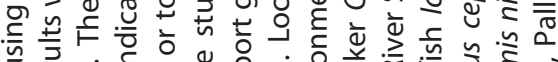

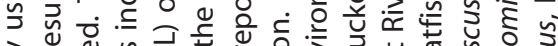

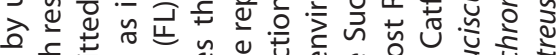

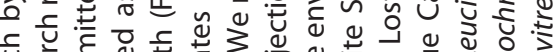

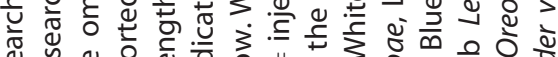
ه

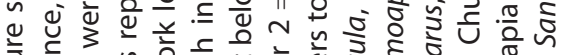

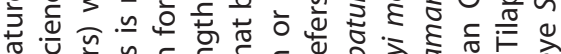

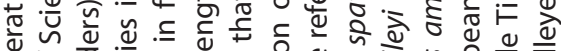

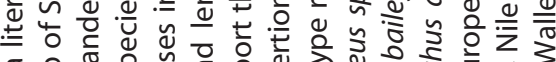

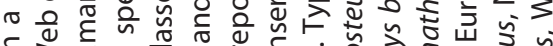
ह 递.

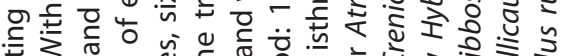

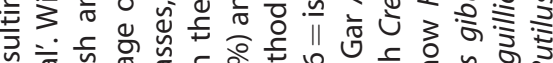

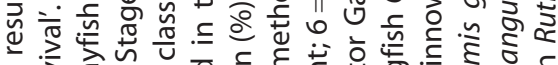

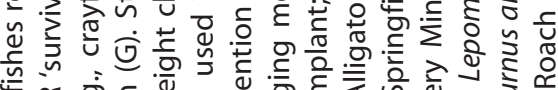

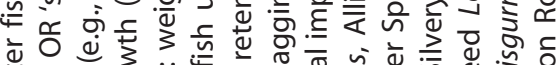

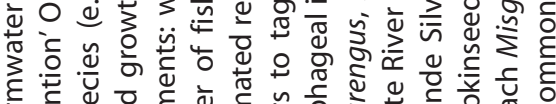

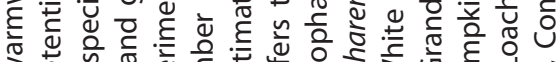

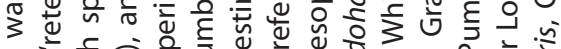

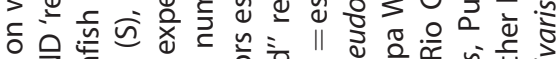

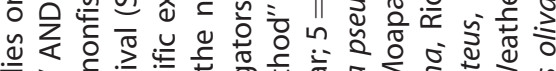
语

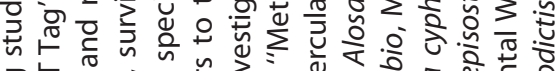
웡둥

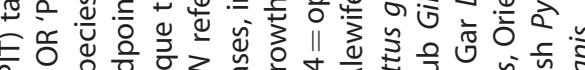

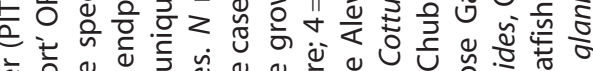

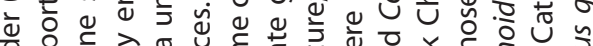

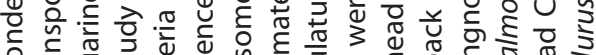

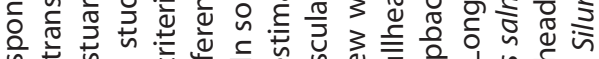

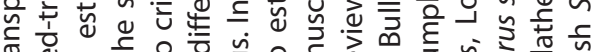

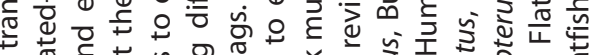

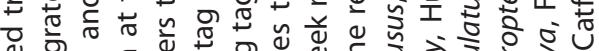

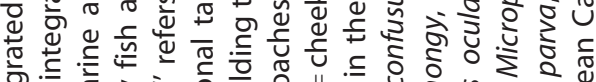

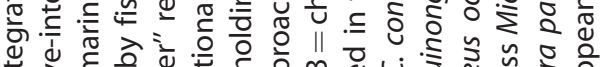

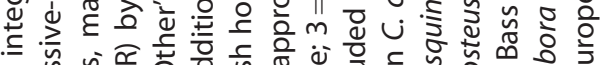

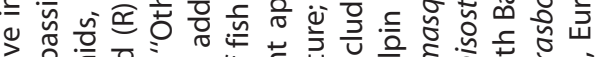

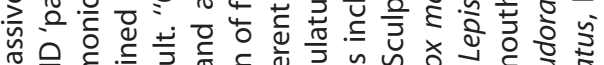

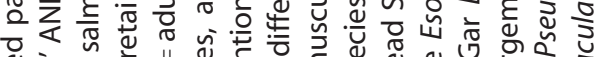

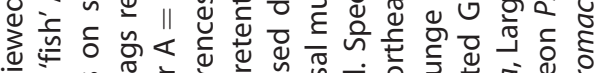

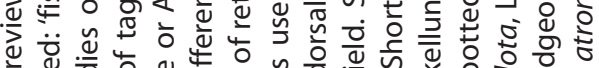

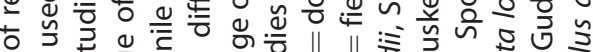

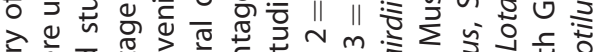

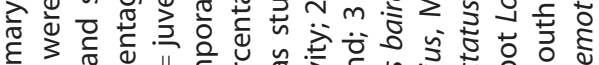

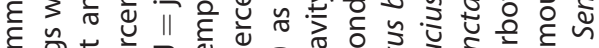

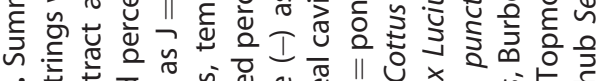

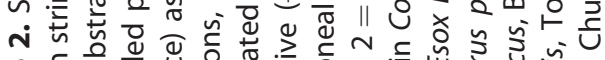

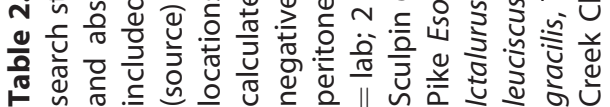

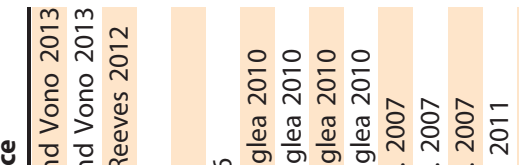

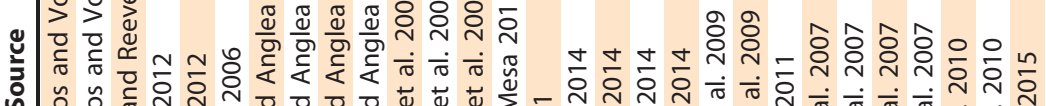

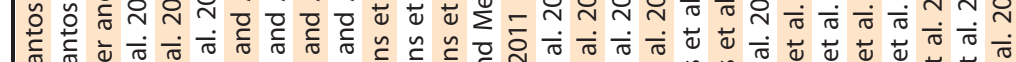

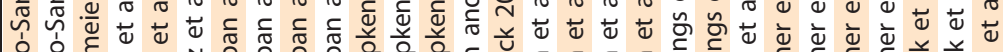

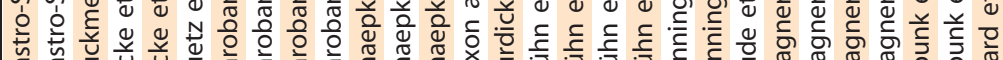

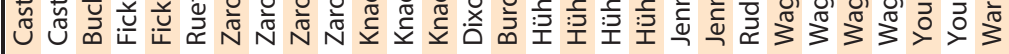
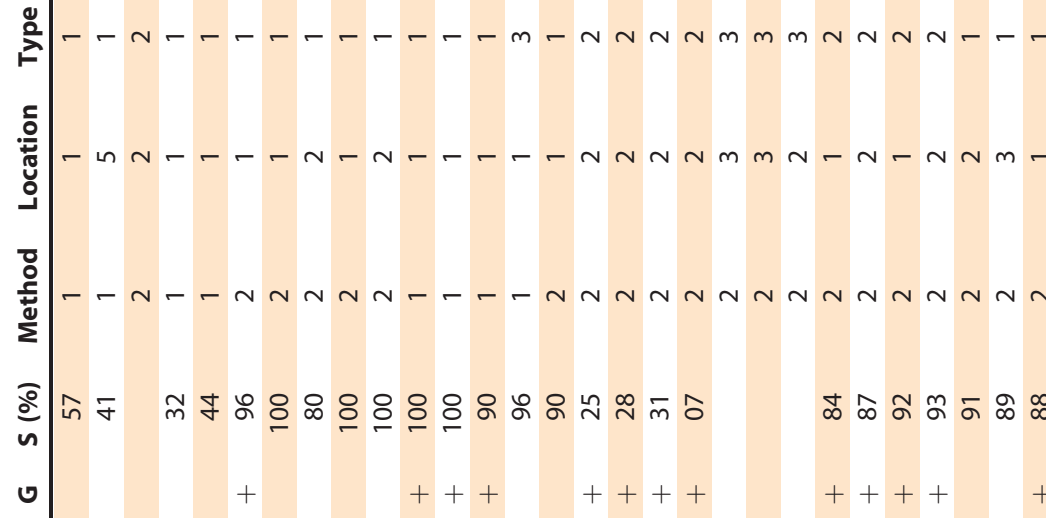

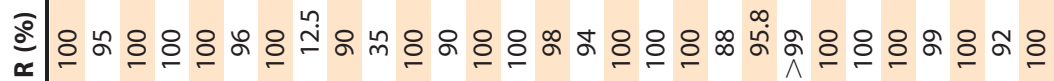

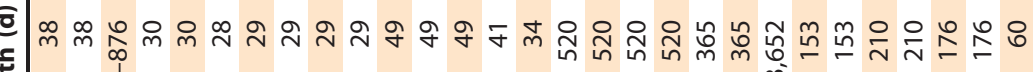
焉 ○

>

$\vec{H} \vec{F} \vec{H} \vec{F} \varepsilon$

है

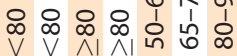
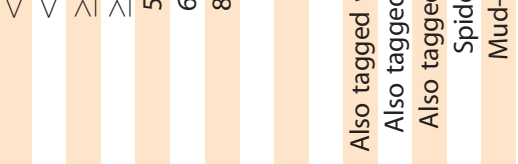

$\ll \ll \ll$

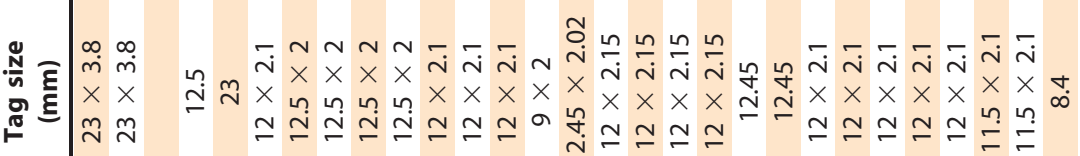

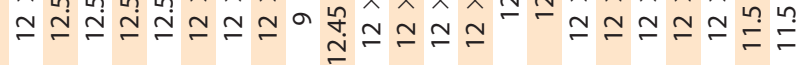

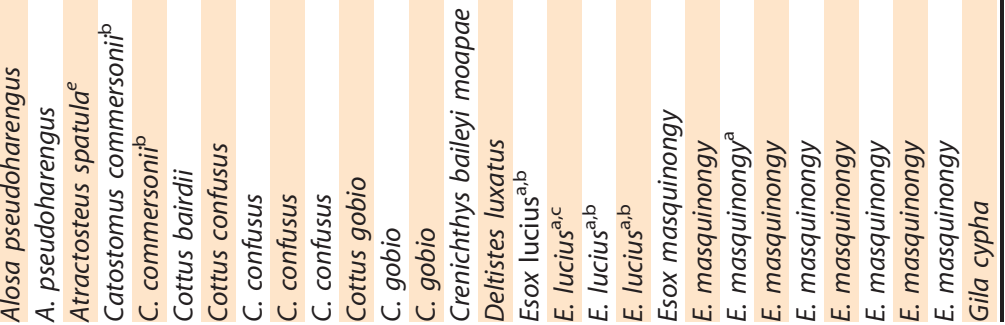




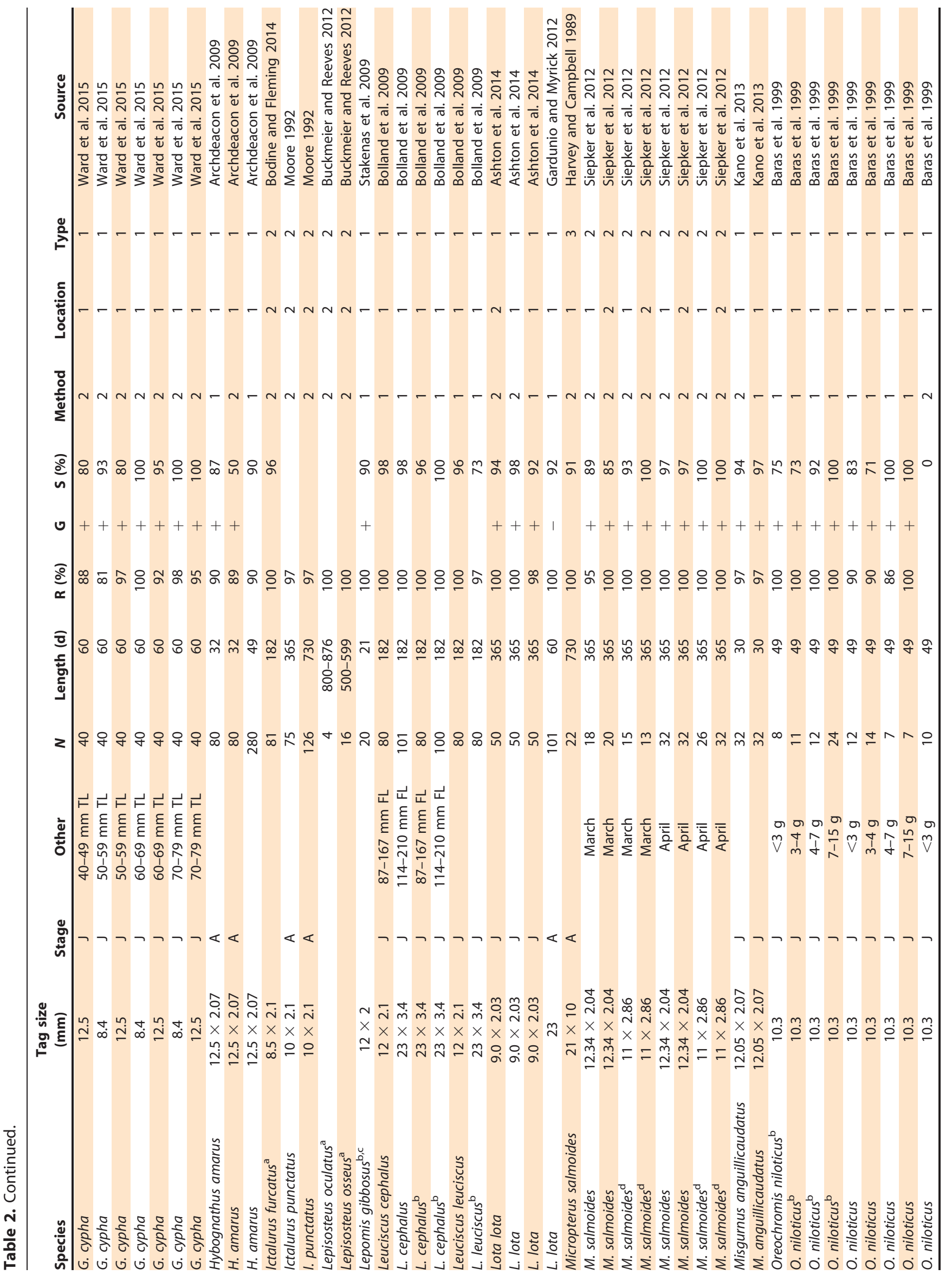




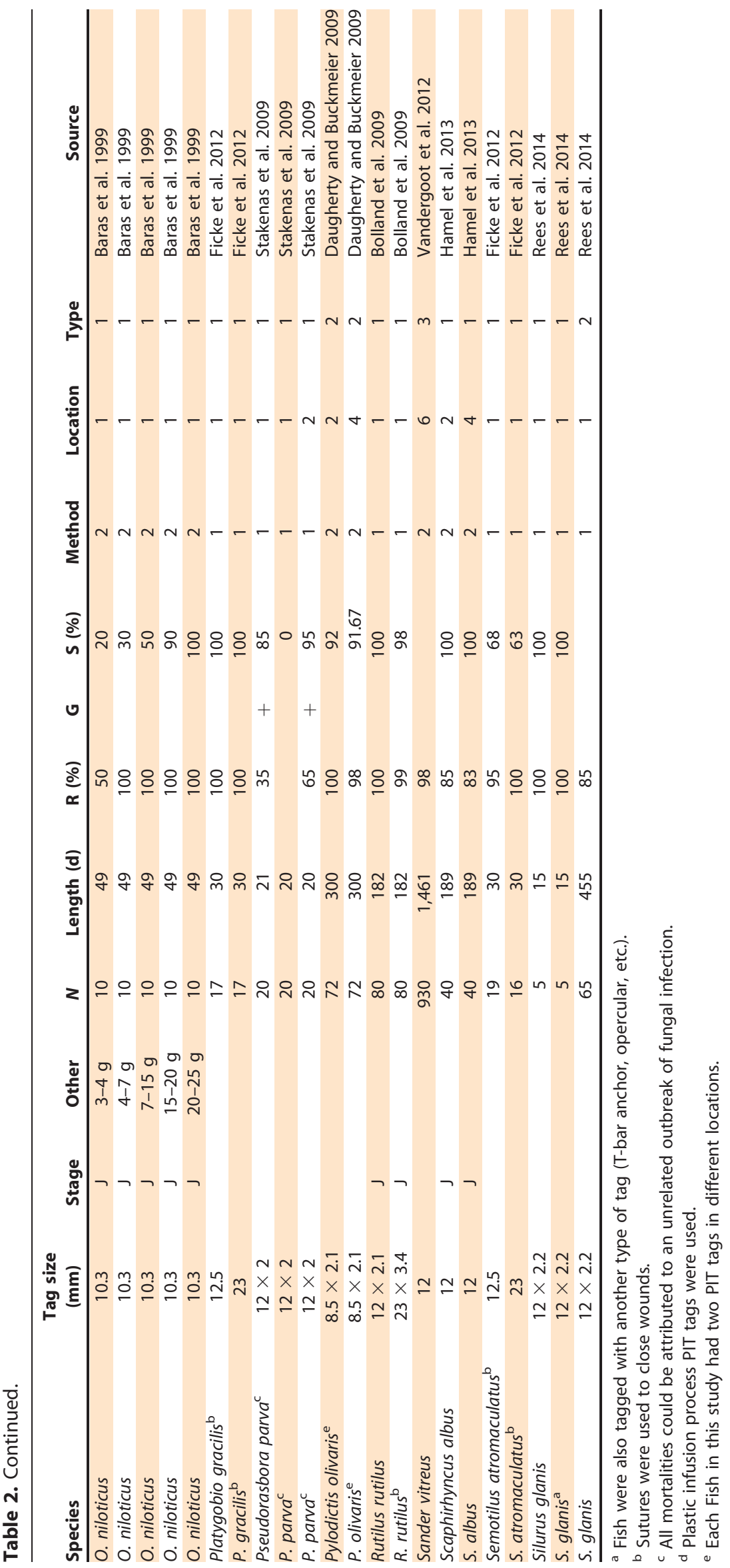


Table 3. Survival (S) and passive integrated transponder (PIT) tag retention (R) of six warmwater fish species that were collected from Flint Creek, Oklahoma, in 2012 to determine PIT tag retention in the laboratory. The six species included in the study were Cardinal Shiner Luxilus cardinalis, Central Stoneroller Campostoma annomalum, Slender Madtom Noturus exilis, Orangethroat Darter Etheostoma spectabile, Greenside Darter Etheostoma blennioides, and Smallmouth Bass Micropterus dolomieu. All fish were tagged in the peritoneum using 12- or 23-mm (tag size) half duplex PIT tags. Survival and PIT tag retention were reported after 30, 60, and 90 d. Survival was reported cumulatively across all time steps, whereas retention was reported as the number of living fish that retained their tags at each time step. We reported the number of fish $(N)$ on occasions where survival or retention was not $100 \%$. Growth $(\mathrm{G}$, weight $_{\text {final }}-$ weight $\left._{\text {initial }}\right)$ was represented as positive $(+)$ or negative $(-)$ after $30 \mathrm{~d}$. We reported the test statistic resulting from Welch's $t$-test where comparisons were made between growth of treatment and control groups (differences between groups).

\begin{tabular}{|c|c|c|c|c|c|c|c|c|c|}
\hline \multirow[b]{2}{*}{ Common name } & \multirow[b]{2}{*}{$N$} & \multicolumn{2}{|c|}{$30 \mathrm{~d}$} & \multicolumn{2}{|c|}{$60 d$} & \multicolumn{2}{|c|}{$90 \mathrm{~d}$} & \multirow[b]{2}{*}{ G } & \multirow[b]{2}{*}{ Differences between groups } \\
\hline & & S (\%) & R (\%) & S (\%) & R (\%) & S (\%) & R (\%) & & \\
\hline Cardinal Shiner & 12 & 100 & 100 & 100 & 100 & 100 & 100 & + & $t_{18.60}=-0.35, P=0.73, r=0.08$ \\
\hline Central Stoneroller & 8 & 100 & 100 & $88(7 / 8)$ & 100 & $88(7 / 8)$ & 100 & + & $t_{9.96}=0.29, P=0.78, r=0.09$ \\
\hline Slender Madtom & 13 & 100 & 100 & 100 & 100 & $N A^{a}$ & NA & - & $t_{21.87}=1.21, P=0.24, r=0.25$ \\
\hline Orangethroat Darter & 9 & $89(8 / 9)$ & 88 & 56 & $80(4 / 5)$ & NA & NA & - & $t_{13.42}=1.41, P=0.18, r=0.36$ \\
\hline Greenside Darter & 3 & 100 & 100 & 100 & 100 & NA & NA & - & $t_{2.33}=0.18, P=0.87, r=0.12$ \\
\hline Smallmouth Bass & 25 & 96 & 100 & 96 & 100 & NA & NA & + & $t_{4.26}=-0.41, P=0.70, r=0.20$ \\
\hline
\end{tabular}

${ }^{\mathrm{a}} \mathrm{NA}=$ not applicable.

analysis suggests that for studies that last up to $60 \mathrm{~d}$, the use of intracoelomic PIT tags to monitor the population of our six species is a viable approach. Above that $60-d$ window, PIT tag retention in other species has shown to consistently be greater than 90\% (e.g., Alligator Gar Atractosteus spatula, Longnose Gar Lepisosteus osseus, Spotted Gar Lepisosteus oculatus, Largemouth Bass; Buckmeier and Reeves 2012; Siepker et al. 2012), suggesting use in long-term experiments may be appropriate. A field-based study of adult Muskellunge Esox masquinongy using a combination PIT and T-bar anchor tags found that even up to 10 y post tagging, the probability of PIT tag loss was less than 1\% (Rude et al. 2011). For our study, injection (implantation via incision in the Smallmouth Bass) into the peritoneal resulted in high tag retention; however, anatomical location and implantation method can highly influence that parameter. For example, for Topmouth Gudgeon Pseudorasbora parva tag loss was much lower in individuals tagged in the flank (35\%) compared to those implanted in the ventral area (65\%; Stakenas et al. 2009). Conversely, a laboratory study of Shorthead Sculpin Cottus confusus found significantly higher retention in tags implanted in the body cavity ( $95 \pm 5.06 \%$ ) compared to those located in base of the spinous dorsal fin (23.75 $\pm 11.39 \%$; Zaroban and Anglea 2010). Tagging method can also partly determine retention. Baras et al. (1999) found use of sutures reduced short-term tag expulsion (and protrusion of viscera) in Nile Tilapia Oreochromis niloticus.

With the exception of Orangethroat Darter, we found survival to $60 \mathrm{~d}$ was high $(\geq 88 \%)$. Our finding agrees with the results of the review where median survival of the 97 experiments was 92\%. Lower survival in Orangethroat Darter may have been due to diet as weight loss was observed in both treatment and control fish. This is in line with the finding of other studies where higher mortalities of PIT tagged fish were potentially driven by external factors rather than the procedure itself (e.g., disease, Castro-Santos and Vono 2013; overwinter mortality, Rees et al. 2014). Significant differences in survival between tagged and control fish were uncom- mon in our review, with the vast majority showing no difference. Whereas we did not explicitly test different methods of implanting the PIT tag, the use of a hypodermic needle did not affect our study species. This is in contrast to Baras et al. (1999) who found higher mortality in Nile Tilapia injected with PIT tags and suggested that this was attributable to their difficulty controlling penetration of the syringe. Given the high survival and retention rate, placing the PIT tag in the peritoneal cavity seems appropriate for the species we studied. Other tagging locations or tag designs may need to be considered for applications where concerns exist about the tags being potentially consumed by humans (e.g., Daugherty and Buckmeier 2009; Siepker et al. 2012).

We found no reduction in growth related to the tagging procedure across any of our study species. However, weight loss was apparent in both control and treatment groups for three of our species: Slender Madtom, Orangethroat Darter, and Greenside Darter. Similarly, our review suggested weight loss in treatment fish was generally matched by growth rates of control fish (e.g., Gardunio and Myrick 2012). Several studies, however, have highlighted an immediate post tagging reduction in growth, which is later compensated by an increased growth rate (e.g., Baras et al. 1999; Ruetz et al. 2006). This initial growth slowdown has been linked to potential "compression of the digestive system" (Navarro et al. 2006). It is also possible that growth reductions may relate to a response by some wild fish to being held in captivity.

The results of our retention and survival trials were largely consistent with data obtained from the literature review. Whereas the studies included in our review are by no means exhaustive (i.e., there are numerous available databases), by undertaking the literature search in a systematic manner, we aimed to reduce bias in study selection. Despite the limitations in the literature pool (e.g., specificity of search terms and absence of gray literature; see Pullin and Stewart 2006), we believe the review highlights some important overall trends. First, 

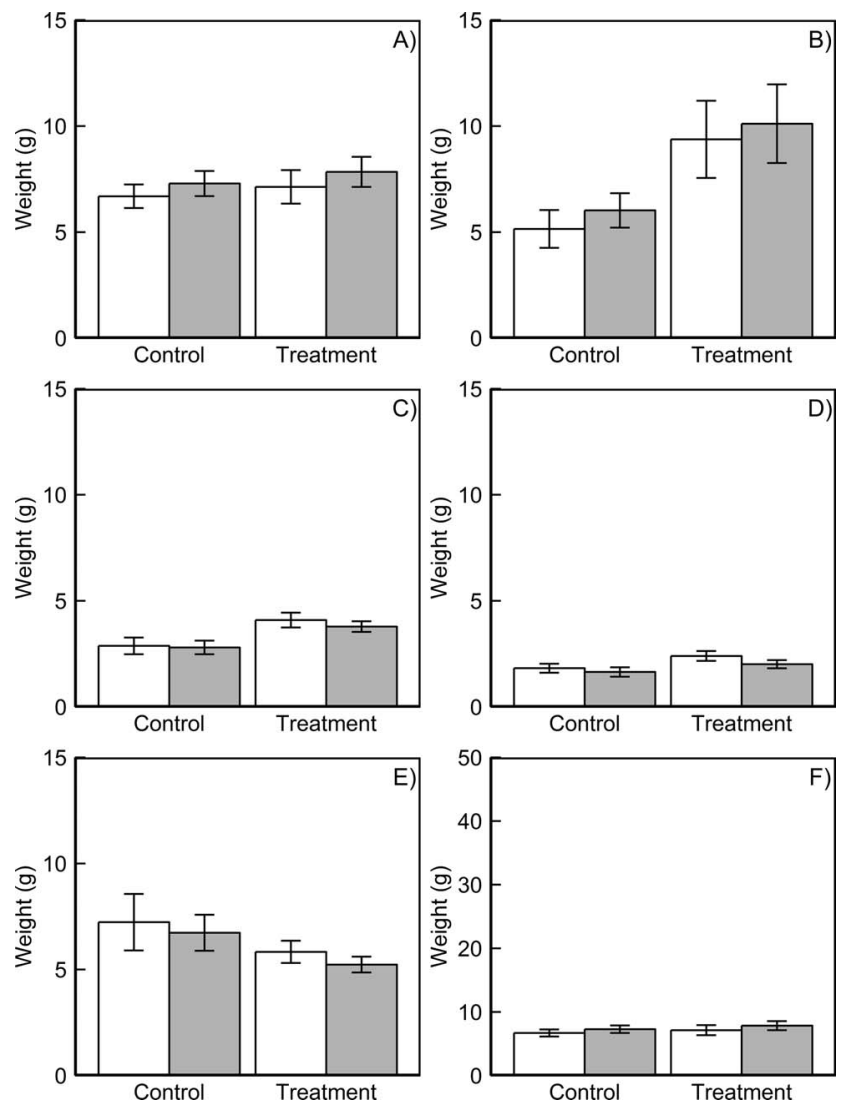

Figure 1. Initial mean weight (white bar, $\pm 95 \%$ confidence limits) and weight after $30 \mathrm{~d}$ (gray bars, $\pm 95 \%$ confidence limits) of six warmwater fish species that were collected from Flint Creek, Oklahoma, in 2012 to determine passive integrated transponder (PIT) tag retention in the laboratory. All treatment fish were tagged in the peritoneum with 12- or 23-mm (tag size) half duplex PIT tags. Control fish were handled in the same manner as treatment fish, but no tagging occurred. Weight was not significantly different between PIT tag treatment and control groups for all species (a = Cardinal Shiner Luxilus cardinalis; $\mathrm{b}=$ Central Stoneroller Campostoma annomalum; $\mathrm{c}=$ Slender Madtom Noturus exilis; $\mathrm{d}=$ Orangethroat Darter Etheostoma spectabile; e = Greenside Darter Etheostoma blennioides; $\mathrm{f}=$ Smallmouth Bass Micropterus dolomieu).

PIT tag retention and survival of tagged fishes were generally high; however, examples of high tag loss (e.g., Stakenas et al. 2009; Zaroban and Anglea 2010) and elevated mortality (e.g., Orangethroat Darter, this study; Ficke et al. 2012) were apparent. This is consistent with Rees et al. (2014) who suggested the "tagging efficiency is largely context-dependent" and therefore comparison across species and methods should be treated with caution (Archdeacon et al. 2009). Survival and retention seem to be a function of a multitude of variables including species (e.g., Stakenas et al. 2009; Ficke et al. 2012), tagging location (e.g., Zaroban and Anglea 2010), and tagging methodology (e.g., Archdeacon et al. 2009). Therefore, it would seem prudent to examine the effect of PIT tag use under controlled conditions before applying alternative tagging methodologies or to new species in situations where the assumptions cannot be tested. Second, although most studies determined the effect of PIT tag use on a combination of tag retention, fish survival or growth, fewer studies have assessed the effect of tag use on fish behavior (but see Knaepkens et al. 2007; Ficke et al. 2012). Third, there is a dearth of information from outside North America and Europe, a phenomenon that has been identified in other areas of ecology (e.g., Wilson et al. 2007; Pyšek et al. 2008; Archer et al. 2014). Given the applications of PIT tags to the conservation and management of fish species, information on a broader range of species from across a wider range of geographic locations would be beneficial. It is also important to recognize that the skill level of persons tagging fish could also affect tag retention and survival and thus warrants consideration. Lastly, examining possible behavioral changes associated with tagging could broaden the use of PIT tagging, especially in smallbodied fishes. Overall, the specific attributes of tagging studies are related to tagging objectives (e.g., survival, growth, and behavior), but reporting information on study duration, weight and length of tagged fish, handling and injection procedures, and use of control fish would benefit a more comprehensive examination of tag effects.

\section{Supplemental Material}

Please note: The Journal of Fish and Wildlife Management is not responsible for the content or functionality of any supplemental material. Queries should be directed to the corresponding author for the article.

Table S1. Spreadsheet containing three tables. Table 1 is a description of field headings used in Tables 2 and 3. Data described are from a laboratory study of passive integrated transponder (PIT) tag retention and survival of six warmwater fish species (scientific names provided in parentheses) that were collected from Flint Creek, Oklahoma, in 2012. All fishes were tagged in the peritoneum with 12 - or $23-\mathrm{mm}$ (tag size) half duplex PIT tags. Table 2 provides data on the total length $(\mathrm{mm})$ and relative growth ( $g$, difference in weight from the beginning to end of trials) of treatment (trt) and control (c) fishes (OTD = Orangethroat Darter Etheostoma spectabile; GRN = Greenside Darter Etheostoma blennioides; SLND = Slender Madtom Noturus exilis; CARD = Cardinal Shiner Luxilus cardinalis; CSTN = Central Stoneroller Campostoma annomalum; and SMB = Smallmouth Bass Micropterus dolomieu). The treatment group was subjected to intracoelomic-placed 12- or 23-mm (tag size) half duplex passive integrated transponder tags. The 23-mm tags were only used to tag Smallmouth Bass due to their larger size at tagging. Control fishes were subject to the same handling as treatment fishes (i.e., anesthetized, measured, and weighed), but they were not tagged. The same person (W.C.M.) conducted all tagging in the laboratory in 2012. Table 3 provides data on the total length $(\mathrm{mm})$ and survival $(30,60$, and $90 \mathrm{~d}$ ) of treatment (trt) and control (c) fishes (OTD = Orangethroat Darter Etheostoma spectabile; GRN = Greenside Darter Etheostoma blennioides; SLND = Slender Madtom 
Noturus exilis; CARD = Cardinal Shiner Luxilus cardinalis; $\mathrm{CSTN}=$ Central Stoneroller Campostoma annomalum; and $\mathrm{SMB}=$ Smallmouth Bass Micropterus dolomieu). The treatment group was subjected to intracoelomic-placed 12- or 23-mm (tag size) half duplex passive integrated transponder tags. The 23-mm tags were only used to tag Smallmouth Bass due to their larger size at tagging. Control fishes were subject to the same handling as treatment fishes (i.e., anesthetized, measured, and weighed), but they were not tagged. The number of fishes surviving is provided if less than $100 \%$.

Found at DOI: http://dx.doi.org/10.3996/122016JFWM-091.S1 (20 KB XLSX).

\section{Acknowledgments}

This research is a contribution of the Oklahoma Cooperative Fish and Wildlife Research Unit (U.S. Geological Survey, Oklahoma Department of Wildlife Conservation, Oklahoma State University, and Wildlife Management Institute cooperating). Funding was provided by the Oklahoma Department of Wildlife Conservation. This study was performed under the auspices of Oklahoma State University animal use protocol AG1110. We thank C. Kemp for providing laboratory assistance. We thank the Associate Editor and three anonymous reviewers for their recommended improvements to the manuscript.

Any use of trade, product, website, or firm names in this publication is for descriptive purposes only and does not imply endorsement by the U.S. Government.

\section{References}

Acolas ML, Roussel JM, Lebel JM, Bagliniere JL. 2007. Laboratory experiment on survival, growth and tag retention following PIT injection into the body cavity of juvenile Brown Trout (Salmo trutta). Fisheries Research 86:280-284. doi: 10.1016/j.fishres. 2007.05.011

Archdeacon TP, Remshardt WJ, Knecht TL. 2009. Comparison of two methods for implanting passive integrated transponders in Rio Grande Silvery Minnow. North American Journal of Fisheries Management 29:346-351. doi: 10.1577/M08-130.1

Archer CR, Pirk CWW, Carvalheiro LG, Nicolson SW. 2014. Economic and ecological implications of geographic bias in pollinator ecology in the light of pollinator declines. Oikos 123:401-407. doi: 10.1111/j.1600-0706. 2013.00949.x

Ashton NK, Anders PJ, Young SP, Cain KD. 2014. Coded wire tag and passive integrated transponder tag implantations in juvenile Burbot. North American Journal of Fisheries Management 34:391-400. doi: 10.1080/02755947.2014.882458

Baras E, Westerloppe L, Melard C, Philippart JC, Benech V. 1999. Evaluation of implantation procedures for PITtagging juvenile Nile Tilapia. North American Journal of Aquaculture 61:246-251. doi: 10.1577/15488454(1999)061<0246:EOIPFP $>2.0 . C O ; 2$
Bodine KA, Fleming P. 2014. Retention of PIT and T-bar anchor tags in Blue Catfish. North American Journal of Fisheries Management 34:68-71. doi: 10.1080/ 02755947.2013.860064

Bolland JD, Cowx IG, Lucas MC. 2009. Evaluation of VIE and PIT tagging methods for juvenile cyprinid fishes. Journal of Applied Ichthyology 25:381-386. doi: 10. 1111/j.1439 0426.2009.01261.x

Bonar SA, Hubert WA, Willis DW. 2009. Standard methods for sampling North American freshwater fishes. Bethesda, Maryland: American Fisheries Society.

Buckmeier DL, Reeves KS. 2012. Retention of passive integrated transponder, T-bar anchor, and coded wire tags in lepisosteids. North American Journal of Fisheries Management 32:573-576. doi: 10.1080/ 02755947.2012 .678968

Burdick SM. 2011. Tag loss and short-term mortality associated with passive integrated transponder tagging of juvenile Lost River Suckers. North American Journal of Fisheries Management 31:1088-1092. doi: 10.1080/02755947.2011.641067

Burnham KP, Anderson DR, White GC, Brownie C, Pollock KH. 1987. Design and analysis methods for fish survival experiments based on release-recapture. Bethesda, Maryland: American Fisheries Society Monographs 5.

Castro-Santos T, Vono V. 2013. Posthandling survival and PIT tag retention by Alewives - a comparison of gastric and surgical implants. North American Journal of Fisheries Management 33:790-794. doi: 10.1080/ 02755947.2013.811130

Cooke SJ, Woodley CM, Eppard MB, Brown RS, Nielsen JL. 2011. Advancing the surgical implantation of electronic tags in fish: a gap analysis and research agenda based on a review of trends in intracoelomic tagging effects studies. Reviews in Fish Biology and Fisheries 21:127-151. doi: 10.1007/s11160-010-9193-3

Daugherty DJ, Buckmeier DL. 2009. Retention of passive integrated transponder tags in Flathead Catfish. North American Journal of Fisheries Management 29:343345. doi: 10.1577/M08-153.1

Dixon CJ, Mesa MG. 2011. Survival and tag loss in Moapa White River Springfish implanted with passive integrated transponder tags. Transactions of the American Fisheries Society 140:1375-1379. doi: 10.1080/ 00028487.2011.621809

Ficke AD, Myrick CA, Kondratieff MC. 2012. The effects of PIT tagging on the swimming performance and survival of three nonsalmonid freshwater fishes. Ecological Engineering 48:86-91. doi:10.1016/j. ecoleng.2011.07.011

Field Z, Field A, Miles J. 2012. Discovering statistics using R. Thousand Oaks, California: SAGE Publications.

Gardunio El, Myrick CA. 2012. Short-term retention rates of passive integrated transponders surgically implanted in Burbot and the effects on survival. North American Journal of Fisheries Management 32:10001004. doi: 10.1080/02755947.2012.711273 
Gibbons JW, Andrews KM. 2004. PIT tagging: simple technology at its best. BioScience 54:447-454. doi: 10. 1641/0006-3568(2004)054[0447:PTSTAI]2.0.CO;2

Hamel MJ, Steffensen KD, Hammen JJ, Pegg MA. 2013. Evaluation of passive integrated transponder tag retention from two tagging locations in juvenile Pallid Sturgeon. Journal of Applied Ichthyology 29:41-43. doi: 10.1111/jai.12103

Harvey WD, Campbell DL. 1989. Technical notes: retention of passive integrated transponder tags in Largemouth Bass brood fish. Progressive Fish-Culturist 51:164-166. doi: 10.1577/1548-8640(1989)051<0164:TNROPI >2.3. $\mathrm{CO} ; 2$

Hauer FR, Lamberti GA. 2006. Methods in stream ecology. 2nd edition. New York: Academic Press.

Hewitt DA, Janney EC, Hayes BS, Shively RS. 2010. Improving inferences from fisheries capture-recapture studies through remote detection of pit tags. Fisheries 35:217-231. doi: 10.1577/1548-8446-35.5.217

Hühn D, Klefoth T, Pagel T, Zajicek P, Arlinghaus R. 2014. Impacts of external and surgery based tagging techniques on small Northern Pike under field conditions. North American Journal of Fisheries Management 34:322-334. doi: 10.1080/02755947. 2014.880762

Jennings MJ, Hatzenbeler GR, Kampa JM. 2009. One-year retention of passive integrated transponders in adult Muskellunge, and applications to broodstock management. North American Journal of Aquaculture 71:330-332. doi: 10.1577/A09-004.1

Jepsen N, Schreck C, Clements S, Thorstad EB. 2005. A brief discussion on the $2 \%$ tag/bodymass rule of thumb. Aquatic Telemetry: Advances and Applications 2005:255-259.

Kano Y, Kawaguchi Y, Yamashita T, Sekijima T, Shimatani Y, Taniguchi Y. 2013. A passive integrated transponder tag implanted by a new alternative surgical method: effects on the Oriental Weather Loach (Misgurnus anguillicaudatus) and application in a small irrigation system. Landscape and Ecological Engineering 9:281287. doi: 10.1007/s11355-011 0152-5

Knaepkens G, Maerten E, Tudorache C, De Boeck G, Eens M. 2007. Evaluation of passive Integrated transponder tags for marking the Bullhead (Cottis gobio), a small benthic freshwater fish: effects on survival, growth and swimming capacity. Ecology of Freshwater Fish 16:404-409. doi: 10.1111/j.1600-0633.2007.00231.x

Lucas M, Baras E. 2000. Methods for studying spatial behaviour of freshwater fishes in the natural environment. Fish and Fisheries 1:283-316. doi: 10.1046/j. 1467 2979.2000.00028.

McCormick MI, Smith S. 2004. Efficacy of passive integrated transponder tags to determine spawningsite visitations by a tropical fish. Coral Reefs 23:570577. doi: 10.1007/s00338-004-0413-y

Moore A. 1992. Passive integrated transponder tagging of Channel Catfish. Progressive Fish Culturist 54:125-127. doi: 10.1577/1548-8640(1992)054<0125:TNPITT $>2.3$. $\mathrm{CO} ; 2$

Navarro A, Oliva V, Zamorano MJ, Gines R, Izquierdo MS, Astorga N, Afonso JM. 2006. Evaluation of PIT system as a method to tag fingerlings of Gilthead Seabream (Sparus auratus L.): Effects on growth, mortality and tag loss. Aquaculture 257:309-315. doi: 10.1016/j. aquaculture.2006.02.072

Pine WE, Pollock KH, Hightower JE, Kwak TJ, Rice JA. 2003. A review of tagging methods for estimating fish population size and components of mortality. Fisheries 28:10-23. doi: 10.1577/1548-8446(2003)28[10:AROTMF]2. $0 . \mathrm{CO} ; 2$

Prentice EF, Flagg TA, McCutcheon CS. 1990a. Feasibility of using implantable passive integrated transponder (PIT) tags in salmonids. American Fisheries Society Symposium 7:317-322.

Prentice EF, Flagg TA, McCutcheon CS, Brastow DF, Cross DC. 1990b. Equipment, methods, and an automated data-entry station for PIT tagging. American Fisheries Society Symposium 7:335-340.

Price AL, Peterson JT. 2010. Estimation and modeling of electrofishing capture efficiency for fishes in wadeable warmwater streams. North American Journal of Fisheries Management 30:481-498. doi: 10.1577/M09122.1

Pullin AS, Stewart GB. 2006. Guidelines for systematic review in conservation and environmental management. Conservation Biology 20:1647-1656. doi: 10. 1111/j.1523-1739.2006.00485.x

Pyšek P, Richardson DM, Pergl J, Jarosik V, Sixtova Z, Weber E. 2008. Geographical and taxonomic biases in invasion ecology. Trends in Ecology \& Evolution 23:237-244. doi: 10.1016/j.tree.2008.02.002

R Core Team. 2012. R: A language and environment for statistical computing. Vienna: $R$ Foundation for Statistical Computing.

Rees EMA, Britton JR, Godard MJ, Crooks N, Miller Jl, Wesley KJ, Copp GH. 2014. Efficacy of tagging European Catfish Silurus glanis (L., 1758) released into ponds. Journal of Applied Ichthyology 30:127-129. doi: 10.1111/jai.12254

Rude NP, Whitledge GW, Phelps QE, Hirst S. 2011. Longterm PIT and t-bar anchor tag retention rates in adult Muskellunge. North American Journal of Fisheries Management 31:515-519. doi: 10.1080/02755947. 2011.593962

Ruetz III CR, Earl BM, Kohler SL. 2006. Evaluating passive integrated transponder tags for marking Mottled Sculpins: effects on growth and mortality. Transactions of the American Fisheries Society 135:1456-1461. doi: 10.1577/T05-295.1

Ryan BA, Smith SG, Butzerin JM, Ferguson JW. 2003. Relative vulnerability to avian predation of juvenile salmonids tagged with passive integrated transponders in the Columbia River estuary, 1998-2000. Transactions of the American Fisheries Society 132:275-288. doi: 10. 1577/1548-8659(2003)132<0275:RVTAPO >2.0.CO;2 
Siepker MJ, Knuth DS, Ball EL, Koppelman JB. 2012. Evaluating a novel passive integrated transponder tag in Largemouth Bass. North American Journal of Fisheries Management 32:528-532. doi: 10.1080/ 02755947.2012.675955

Skalski GT, Gilliam JF. 2000. Modeling diffusive spread in a heterogeneous population: a movement study with stream fish. Ecology 81:1685-1700. doi: 10.1890/0012 9658(2000)081[1685:MDSIAH]2.0.CO;2

Skalski JR, Buchanan RA, Griswold J. 2009. Review of marking methods and release-recapture designs for estimating the survival of very small fish: Examples from the assessment of salmonid fry survival. Reviews in Fisheries Science 17:391-401. doi: 10.1080/ 10641260902752199

Stakenas S, Copp GH, Scott DM. 2009. Tagging effects on three non-native fish species in England (Lepomis gibbosus, Pseudorasbora parva, Sander lucioperca) and of native Salmo trutta. Ecology of Freshwater Fish 18:167-176. doi: 10.1111/j.1600 0633.2008.00339.x

Teixeira A, Cortes RMV. 2007. PIT telemetry as a method to study the habitat requirements of fish populations: application to native and stocked Trout movements. Hydrobiologia 582:171-185. doi: 10.1007/s10750-0060551-z

Vandergoot CS, Brenden TO, Thomas MV, Einhouse DW, Cook HA, Turner MW. 2012. Estimation of tag shedding and reporting rates for Lake Erie jaw-tagged Walleyes. North American Journal of Fisheries Management 32:211-223. doi: 10.1080/02755947.2012. 672365
Wagner CP, Jennings MJ, Kampa JM, Wahl DH. 2007. Survival, growth, and tag retention in age-0 Muskellunge implanted with passive integrated transponders. North American Journal of Fisheries Management 27:873-877. doi: 10.1577/M06-196.1

Walters CJ, van Poorten BT, Coggins LG. 2012. Bioenergetics and population dynamics of Flannelmouth Sucker and Bluehead Sucker in Grand Canyon as evidenced by tag recapture observations. Transactions of the American Fisheries Society 141:158-173. doi:10. 1080/00028487.2012.654891

Ward DL, Persons WR, Young KL, Stone DM, Vanhaverbeke DR, Knight WK. 2015. A laboratory evaluation of tagging-related mortality and tag loss in juvenile Humpback Chub. North American Journal of Fisheries Management 35:135-140. doi: 10.1080/02755947. 2014.986345

Wilson JRU, Procheș S, Braschler B, Dixon ES, Richardson DM. 2007. The (bio)diversity of science reflects the interests of society. Frontiers in Ecology and the Environment 5:409-414. doi: 10.1890/060077.1

Younk JA, Herwig BR, Pittman BJ. 2010. Short- and longterm evaluation of passive integrated transponder and visible implant elastomer tag performance in Muskellunge. North American Journal of Fisheries Management 30:281-288. doi: 10.1577/M08-257.1

Zaroban DW, Anglea SM. 2010. Efficacy of using passive integrated transponder technology to track individual Shorthead Sculpins. Western North American Naturalist 70:218-223. doi: http://dx.doi.org/10.3398/064.070. 0208 